\section{CASES OF HYPOPITUITARISM}

BY

\author{
R. T. COOKE, M.D.
}

Pathologist, Hartlepools Hospital Services Joint Committee AND

\author{
H. L. SHEEHAN, M.D., D.Sc., F.R.C.P. \\ Professor of Pathology, University of Liverpool
}

The description of the syndrome of hypopituitarism has been modified considerably in recent years. Certain so-called "characteristics," such as emaciation and progeria, which were previously regarded as essential to the diagnosis, are now recognized as being so unusual that their occurrence even throws doubts on the diagnosis. The four photographs of true cases of hypopituitarism illustrate the normal state of nutrition of these patients and the absence of body hair. The purpose of this paper is to present a few reliable examples of hypopituitarism in order to illustrate some aspects of the symptomatology and pathology. A general account of the syndrome is not necessary here, as the ground has been covered in a recent review of the literature (Sheehan and Summers, 1949). Patients may show predominantly one aspect or other of the syndrome or any combination of these: genital superinvolution, deficiency of thyroid or adrenal cortical function, hypoglycaemia. The irregularities seem to depend on two factors: (1) the amount of anterior pituitary parenchyma which has been destroyed, and (2) the time which has elapsed. since the destruction, because the secondary effects on other endocrines may take years to reach a grave degree.

The first four of our cases have pathological proof of the pituitary lesion. In the other four the history gives very strong presumptive evidence of the sudden destruction of most of the anterior lobe by a post-partum necrosis. The subsequent clinical course in these four patients was typical, though the syndrome was in some respects incomplete. Many of the more significant biochemical and haematological data in the following records are given in Tables I and II.

\section{Case 1}

This patient was a man who died in 1949 at the age of 67 . His symptoms fell into two groups: (a) those due to small cerebral softenings, and $(b)$ those due to hypopituitarism.

(a) He was quite well until 1941, when he had a slight "stroke" which produced great weakness of the legs. From
TABLE I.-Insulin-tolerance Tests $(0.03$ units Insulin I.V. per $\mathrm{kg.)}$

\begin{tabular}{|c|c|c|c|c|c|c|c|}
\hline \multirow{3}{*}{ Minutes } & & \multicolumn{6}{|c|}{ Blood Sugars: mg. per $100 \mathrm{ml}$. } \\
\hline & & \multirow{2}{*}{ Case 1} & \multirow{2}{*}{ Case 3} & \multirow{2}{*}{ Case 5} & \multicolumn{2}{|c|}{ Case 6} & \multirow{2}{*}{ Case 8} \\
\hline & & & & & Age 40 & Age 41 & \\
\hline $\begin{array}{r}0 \\
30 \\
60 \\
90 \\
120\end{array}$ & $\begin{array}{l}\because \\
\because \\
\because \\
\therefore\end{array}$ & $\begin{array}{l}95 \\
48 \\
45 \\
50 \\
-\end{array}$ & $\begin{array}{l}60 \\
30 \\
28 \\
27\end{array}$ & $\begin{array}{l}64 \\
55 \\
38 \\
45 \\
41\end{array}$ & $\begin{array}{l}62 \\
42 \\
42 \\
54\end{array}$ & $\begin{array}{l}86 \\
56 \\
47 \\
54 \\
62\end{array}$ & $\begin{array}{l}70 \\
41 \\
62 \\
67 \\
72\end{array}$ \\
\hline
\end{tabular}

1946 onwards he had several similar slight strokes, developed symptoms of Parkinsonism, and was confined to bed from the summer of 1948 as a result of flexion deformities of the knees. In the last two months he had urinary incontinence.

(b) In 1944 he became very weak and was in hospital with a diagnosis of myxoedema, hypochromic anaemia, and vitaminC deficiency. At that time he had achlorhydria. His symptoms improved slightly after treatment with thyroid and iron, but were worse again in 1946. At his last admission to hospital, two months before death, it was noted that his skin was very white, soft, and smooth. His head hair was normal and grey, but the eyebrows were very scanty over the outer half. A moustache was present, but the beard grew so slowly that shaving was needed only about every 10 days. There was no hair on axillae, pubis, or trunk. Nutrition was normal. The Wassermann reaction was negative and the C.S.F. normal. Radiological abnormalities were not found.

He became comatose one evening and died next morning.

\section{Pathological Findings} life.

At necropsy the external appearances were the same as during

The pituitary was of normal size, but on section the anterior lobe had a grey gelatinous appearance with a small brown nodule in front. Histologically the anterior lobe consisted almost entirely of fibrous tissue, which was rather loose centrally but more condensed towards the surface. Near the interlobar septum there was a small fibrotic mass of remaining parenchyma cells, representing not more than $5 \%$ of the original anterior lobe. Most of these cells were chromophobes and eosinophils, with only occasional basophils. At the front of the scarred anterior lobe there was a small adenoma $2.5 \mathrm{~mm}$. in diameter; this consisted of small round cells arranged in pseudo-rosettes, and appeared to be a variant of a chromophobe adenoma. The posterior lobe was normal, but had much basophil infiltration. The arteries supplying the pituitary appeared healthy.

The thyroid $(9.4 \mathrm{~g}$.) was small and consisted of very atrophic acini containing colloid. The adrenals $(2.4 \mathrm{~g}$. and $2.6 \mathrm{~g}$.) had a thin cortex $(0.2$ to $0.4 \mathrm{~mm}$.), with normal arrangement apart

TABLE II.-Haematological and Biochemical Data

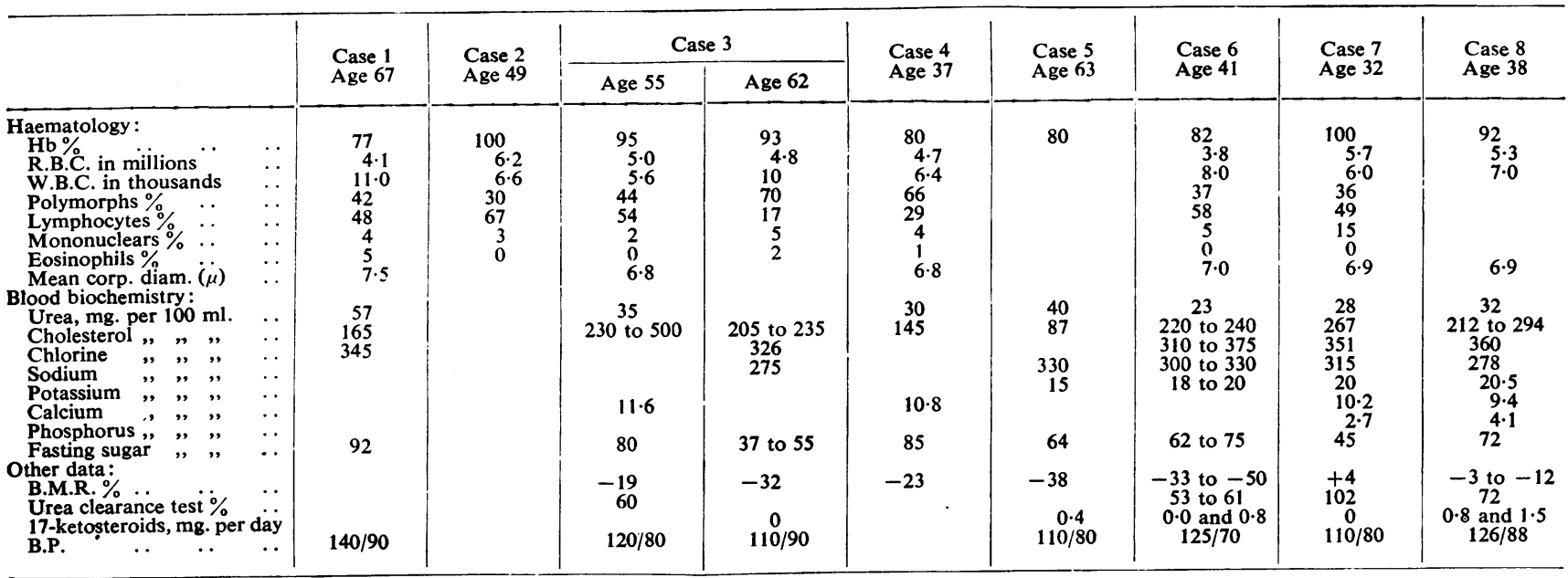


from the atrophy, and normal lipoid content. The capsule was very thick, and there was a fibrous band between the cortex and the medulla. The medulla appeared normal. The testes (right $9.1 \mathrm{~g}$.) had very atrophic hyalinized remains of tubules, with much fibrosis between them, and no interstitial cells. The prostate was very small, with atrophic glands remaining in apparently normal muscular tissue. The parathyroids were large and orange-coloured; they showed chief cells and numerous oxyphil cells. The pancreas was small; it contained large numbers of islets of normal size and healthy appearance. No remains of the thymus could be found.

The brain showed numerous small areas of old softening in the right basal ganglia. There was much atheroma of cerebral arteries. The heart $(295 \mathrm{~g}$.) had dilated flabby ventricles, similar to those seen in myxoedema. Some old scarring of the mitral valve was present. The liver $(850$ g.) and spleen $(85$ g.) were small. The kidneys $(65$ g. and 53 g.) were atrophied but without fibrosis. The stomach showed a puckered but incompletely healed peptic ulcer on the lesser curvature.

Comment.-There is no direct evidence regarding the cause of the severe fibrous replacement of the anterior pituitary. The position of the residue of parenchyma, the absence of any scarring of the posterior lobe, and the associated cerebral lesions suggest that the original lesion of the anterior lobe was an is $\mathrm{ch}$ a e $\mathrm{mic}$ necrosis. It is of interest that the small chromoph o be adenoma appeared quite healthy despite the gross changes around
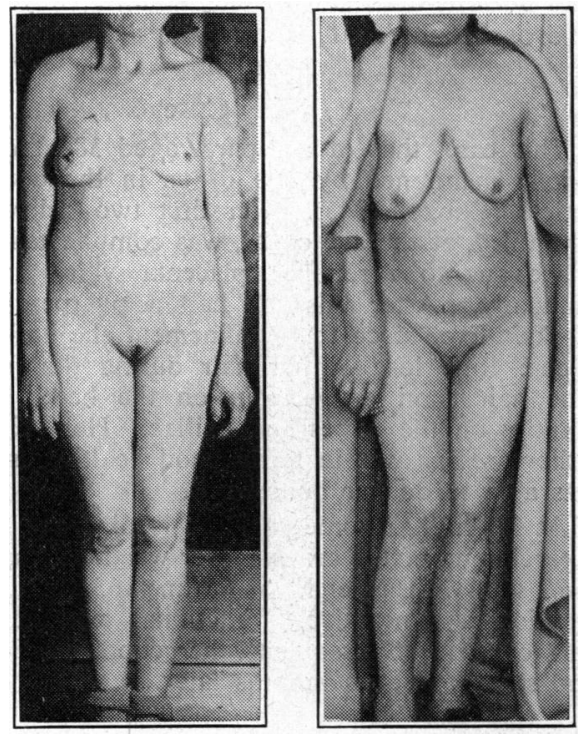

Typical cases of hypopituitarism.
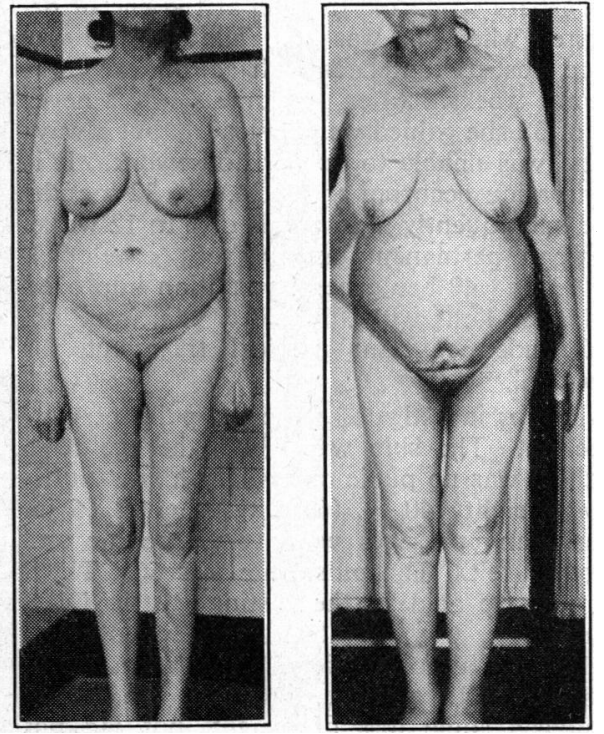

During the last few months she was vaguely unwell. She stayed in bed on the day before death, and had vomited and become stuporous. She died in coma while being taken to hospital after an illness lasting about 24 hours.

\section{Pathological Findirgs}

At necropsy the body was of normal nutrition. The face was very pale; head hair was normal, eyebrows were scanty, and there was no pubic or axillary hair. The breasts were of normal size.

The sella turcica appeared empty on ordinary inspection. The infundibular stalk was plump and was attached to a tiny nociule of tissue lying in contact with and just in front of the dorsum sellae. Microscopical examination was made of this nodule and of the dura lining the floor of the sella. This showed that the nodule consisted of the fibrosed remains of the posterior lobe of the pituitary. In the dura covering the floor of the sella there was a very thin lamina of anterior lobe parenchyma. This was assessed as about $4 \%$ of the normal amount. It consisted of rather shrunken cells with neutrophil cytoplasm; there were no clear examples of eosinophil or basophil cells. Above it there was a thin shaggy layer of acellular fibrous tissue. The stalk was normal and vascular; it had a thin pars tuberalis of small shrunken cells, and there was a small focus of fibrinoid change on the back of the stalk. The hypothalamus appeared normal.

The thyroid weighed $13 \mathrm{~g}$. It showed considerable fibrosis and numerous areas of lymphocytic infiltration; the remaining acini were very small and atrophic, with very flat epithelium but with normal colloid in the lumen. The adrenals weighed $3.1 \mathrm{~g}$. together. The fibrous capsule was very much thickened. The cortex was represented only by short columns of cells with no zonal arrangement and with only little lipoid. There was no fibrosis between these cell columns except directly beneath the capsule. The thickness of the cortex varied from 0.05 to $0.2 \mathrm{~mm}$. There was no fibrosis between cortex and medulla. The medulla appeared small but normal histologically.

The uterus was very small, weighing $11 \mathrm{~g}$., and its overall length was $45 \mathrm{~mm}$. The myometrium was $4 \mathrm{~mm}$. thick and was extensively fibrosed; the remaining muscle cells had very little cytoplasm. The endometrium was $0.1 \mathrm{~mm}$. thick, and histologically was just a thin fibrosed layer in which there were scattered small cystic glands. The ovaries were shrunken to flat disks made up of medullary tissue covered by a thin layer of cortical stroma in which there were no germinal cells or corpora albicantia. The heart $(250$ g.) showed severe mitral stenosis. The liver $(1,220 \mathrm{~g}$.) and spleen $(260 \mathrm{~g}$.) were rather congested. The pancreas $(70 \mathrm{~g}$.) contained very numerous islets which were all small. The kidneys were small (70 and $80 \mathrm{~g}$.) but were normal histologically, apart from minor ischaemic scars at the surface. The aortic lymph nodes had no germinal centres in the follicles.

Comment.-This is an example of the pathological lesion which is described, for lack of a better term, as "empty count showed no anaemia. She complained of pains in the knees, and was very round-shouldered. Her weight was $116 \mathrm{lb}$. $(52.6 \mathrm{~kg}$ ). 
sella," and which seems to be the final scarred stage of some previous acute or subacute pathological process, such as giant-cell granuloma, cystic degeneration, or, in some cases, an ischaemic necrosis. In the present case there is no pathological evidence of giant-cell granuloma or any history to indicate an ischaemic necrosis. The rather degenerate appearance of the shaggy fibrous tissue which lies above the pituitary residue suggests that the original lesion may well have been a cystic degeneration which had progressed so far that only a thin layer of the lower surface of the gland remained.

The duration of the lesion is uncertain. The onset of the amenorrhoea at the early age of 24 suggests that some pituitary damage may have occurred then, but there were no further symptoms which could be attributed to hypopituitarism until about the age of 35 to 40 . Presumably the lesion was of slow progressive development. The manner of death was typical of a severe hypopituitarism which has resulted in great atrophy of the adrenal cortex.

\section{Case 3}

This patient was a 1-para who died in 1948 at the age of 62 . Her pregnancy occurred when she was 26 . The delivery was complicated by severe post-partum haemorrhage, and she was dangerously ill for some weeks. After that time she was never well. Up to the age of 32 she gained weight steadily but always felt cold and tired and was unable to do her housework. It is of interest that menstruation occurred at 13,24 , and 32 months after the delivery and subsequently at intervals of 6 to 12 weeks to the age of 32 , when permanent amenorrhoea developed. Between the ages of 33 and 40 her general condition improved enough for her to do her housework, but after this interlude she was an invalid under constant medical treatment for "weakness and anaemia."

At the age of 55 she was investigated from the point of view of endocrine dysfunction. The skin was white, the eyebrows were very thin, and there was no pubic or axillary hair. Nutrition was satisfactory : weight $140 \mathrm{lb}$. $(63.5 \mathrm{~kg}$.), height 65 in $(165 \mathrm{~cm}$.). The uterus and passages were very atrophic and the thyroid could not be felt. The pulse rate was 66 . There was some free hydrochloric acid in the fasting gastric juice. The Wassermann reaction was negative, and radiological examination showed no abnormalities. Treatment with thyroxine raised the B.M.R. a little, lowered the blood cholesterol, and produced some loss of weight, but did not improve her general condition. After this she gradually developed general appearances suggesting myxoedema, with puffy eyes, a white face, dry but not scaly skin, some loss of head hair, great physical weakness, and very slow cerebration.

At age 62 a series of attacks of vomiting began and she was found to have hypoglycaemia, low blood sodium and chlorine, and other biochemical disturbances. Her weight was still $140 \mathrm{lb}$. Suitable treatment was instituted, but she developed jaundice (apparently an infective hepatitis), became moderately oedematous, and died two weeks later.

\section{Pathological Findings}

At necropsy the external appearances were as during life. The sella turcica appeared empty on first inspection, but more detailed examination showed a normal pituitary stalk attached to the shrunken posterior lobe at the back of the sella. Histological examination of the dura covering the floor of the sella showed a very thin lamina of anterior pituitary parenchyma just in front of the posterior lobe. This was $0.1 \mathrm{~mm}$. in thickness and about $3 \mathrm{~mm}$. long, and was estimated to represent about $5 \%$ of the original anterior lobe. All three types of cell could be identified, but most of the cells appeared to be of a weakly basophil variety. The surrounding fibrous tissue was loose and showed no inflammatory lesions.

The thyroid $(14 \mathrm{~g}$.) showed atrophic acini full of colloid, with much fibrosis and lymphoid infiltration. The adrenals (9.4 g. together) had thinning of the cortex to 0.3 to $0.4 \mathrm{~mm}$., with considerable distortion of its pattern. The capsule showed great fibrous thickening, and the cortex was separated from the medulla by a fibrous layer. The parathyroids were of normal size, but contained no oxyphil cells. The uterus $(58 \mathrm{~g}$.) and ovaries (2.6 g. together) were atrophic, but there was still a thin endometrium remaining. The pancreas $(90 \mathrm{~g}$.) had islets of the normal number and size, but the $\beta$ cells showed hydropic change. The viscera were not atrophied; heart $360 \mathrm{~g}$., liver 1,300 g., kidneys $200 \mathrm{~g}$. together, spleen $180 \mathrm{~g}$. The only pathological lesions were a healing hepatitis, much cystitis with some old pyelonephritic scarring of the kidneys, and some recent infarcts in the lungs.

Comment.-This was pathologically a fairly typical example of an "empty sella." The probable aetiology in this case was a large post-partum necrosis of the anterior pituitary 36 years before the patient's death. It is, however, impossible to be sure that no further atrophic change developed in the gland during the last few years. The case illustrates some of the vagaries of the syndrome. Permanent amenorrhoea did not develop until six years after the delivery, and the syndrome was an incomplete one for many years. During the last few years she showed a myxoedematous type of hypopituitarism, but terminally had serious adrenal cortical insufficiency. The absence of microsplanchnia at necropsy is a further point of interest.

\section{Case 4}

This case, that of a 3-para, aged 38 at death in 1942, was briefly mentioned by one of us in the course of a previous article (Cooke, 1945). Her first two deliveries were normal. The third, at the age of 29 , was complicated by much haemorrhage due to a retained placenta which had to be removed manually. After this she had a puerperal infection for six weeks. Ever since this confinement she had complete amenorrhoea. She lost all her hair during the puerperal infection. The hair soon grew again on the head, but returned only scantily on the pubes and axillae. Her skin was always dry. Otherwise she was in fairly good health, remained plump, and was able to do her housework.

At 37 she had some vaginal bleeding and was found to have a carcinoma of the cervix. Her weight at that time was $146 \mathrm{lb}$. $(66.2 \mathrm{~kg}$.) with a height of 65 in. $(165 \mathrm{~cm}$.). The Wassermann reaction was negative. Fractional test meal showed normal acid content. Subsequently her condition deteriorated steadily and she died seven months later.

\section{Pathological Findings}

At necropsy she was thin but not cachectic. The pituitary weighed $0.25 \mathrm{~g}$. Its anterior lobe was considerably shrunken and flattened. Histologically it consisted almost entirely of a layer of loose fibrillary connective tissue, with a very thin layer of anterior pituitary parenchyma on the upper and lower surfaces of the scar. The total amount of this parenchyma was estimated as less than $10 \%$ of the original gland. The cells were of the three staining types in their usual proportions and appeared quite healthy. The posterior lobe was normal, apart from a small area of scarring at its posterior surface. The stalk was normal in size and structure.

The other endocrines and viscera were small : thyroid $12.4 \mathrm{~g}$., ovaries $3.5 \mathrm{~g}$. together, heart $220 \mathrm{~g}$., liver $1,240 \mathrm{~g}$., pancreas 55 g., kidneys together $135 \mathrm{~g}$., spleen $120 \mathrm{~g}$. The liver showed gross fatty change and the kidneys some pyelonephritis. The uterus was $65 \mathrm{~mm}$. long, with myometrium 6 to $9 \mathrm{~mm}$. thick ; the cervix and surrounding structures were replaced by widespread carcinoma.

Comment.-The patient had a subtotal destruction of the anterior pituitary, almost certainly the result of a postpartum necrosis nine years before death. This had not as yet given rise to a severe degree of hypopituitarism; she seems to have been in relatively good health apart from the amenorrhoea and the lack of pubic and axillary hair. The terminal we:ght loss was a result of the carcinoma, and is clearly not attributable to the hypopituitarism. 


\section{Case 5}

A 4-para, aged 63 in 1949, had three normal deliveries followed by lactation. Her fourth delivery, at 35, was complicated by ante-partum and post-partum haemorrhage. Her baby was stillborn and her breasts involuted at once without even becoming tense. After the delivery she had permanent amenorrhoea. The pubic hair, which had been shaved at the delivery, did not grow again and the axillary hair disappeared gradually soon after. Sweating, which had been rather heavy previously, ceased entirely after the delivery. She became slow in her movements, but was able to continue her housework. Her weight remained unchanged.

At age 63 she had a short attack of diarrhoea which was followed by semicoma for about two days. On subsequent examination her nutrition appeared to be normal-115 lb. $(52.2 \mathrm{~kg}),. 61 \mathrm{in} .(155 \mathrm{~cm}$.). The face was extremely white, though the blood showed only a minor anaemia. The head hair was brown and of fine texture, the eyebrows were very thin, and the axillary and pubic hair were absent, though a few short hairs were present on the labia. The skin was dry everywhere and the axillae were free from any greasiness. The thyroid was impalpable. The pulse rate was 60 . Examination of C.S.F. and urine, and full radiological investigations, showed no abnormality. The Wassermann reaction was negative.

Comment.- This patient seems to have had a subtotal post-partum necrosis 28 years ago involving about $90 \%$ of the anterior pituitary. The biochemical tests indicate a rather severe hypopituitarism, and this is supported by most of the history and the clinical findings. On the other hand, she is physically and mentally more active than is usual in patients with very severe degrees of pituitary loss. However, the recent episode of coma is of serious prognostic import.

\section{Case 6}

This patient, a 3-para aged 42 in 1948 whose earlier health was good, weighed $114 \mathrm{lb}$. (51.7 kg.) at 21 and $98 \mathrm{lb}$. (44.5 kg.) at 28, when she married. The last delivery, at the age of 36 , was complicated by severe post-partum haemorrhage. There was no lactation or swelling of the breasts in the puerperium. At the end of the puerperium she had an attack of confusional insanity lasting two days, but recovered completely.

From the time of the delivery she had complete amenorrhoea, absence of libido, physical weakness so severe that she was unable to do simple housework, great sensitivity to cold, and absence of sweating of the axillae and of the rest of the body. At 40 she had a "nervous breakdown" and was three months in a mental hospital. Examination shortly afterwards showed extreme atrophy of the uterus, cervix, vagina, and vulva. There was no hair in the axillae or on the mons, but a small amount remained on the labia majora. The eyebrows were very thin, but the head hair was normal. The skin was very pale. She was of normal nutrition (weight $105 \mathrm{lb} .-47.6 \mathrm{~kg}$.- - height $60 \mathrm{in}$. $-152 \mathrm{~cm}$.) and the breast contours were normal. Mentally she was rather quiet and apathetic, and replied slowly to questions. The glucose-tolerance test showed a flat curve. There was a histamine-fast achlorhydria.

Comment.-The patient seems to have had a severe postpartum necrosis six years before admission. The adrenal cortex still maintains satisfactory electrolyte balance, but the other biochemical tests show significant hypopituitarism.

\section{Case 7}

A 1-para aged 32 in 1945 had her only pregnancy at the age of 19. The delivery was by forceps ; no further obstetric details are available. She was in bed for two months afterwards. The baby was breast-fed for three months. Ever since the delivery she had complete amenorrhoea and absence of libido. The pubic hair, which was shaved at the delivery, never returned. She never regained her strength and became very sensitive to cold. Her face, previously ruddy, became remarkably white. Her weight remained unchanged and she lost no teeth.
Examination showed severe atrophy of the entire genital tract; the cervix was flush with the vaginal vault and the uterus was too small for palpation. The head hair and eyebrows were normal, but there was no axillary hair and practically no pubic hair. The nutrition was normal and the patient did not appear apathetic. A fractional test meal showed a histamine-labile achlorhydria, and a glucose-tolerance test gave a flat curve.

Comment.-This patient presumably had a moderatesized post-partum necrosis, leading to the destruction of perhaps $80 \%$ of the anterior lobe. This resulted in a partial syndrome involving the gonads, the genital tract, and the androgenic functions of the adrenals severely. On the other hand, the electrolyte balance and the functions of the thyroid remained almost unaffected. It is of considerable interest that this patient lactated after the delivery.

\section{Case 8}

This patient was a 5-para aged 38 in 1946. Her n̂rst four deliveries, at the age of 25 to 32, were normal. At 34 she had a twin pregnancy which terminated with severe accidental haemorrhage and profound shock. After this delivery she had permanent amenorrhoea but the libido was unchanged. The pubic hair disappeared, but the hair on the vulva remained; there had never been axillary hair. The eyebrows became thinned, her face became remarkably pale, and the areolar pigment disappeared from the nipples. Her weight remained unchanged $-100 \mathrm{lb}$. $\left(45.4 \mathrm{~kg}\right.$.), height $58 \frac{1}{2}$ in. $(149 \mathrm{~cm}$.). There was no undue sensitivity to cold. She was always tired, but was able to do some housework. She was not apathetic, and her speech was not hesitant or slow.

On examination the uterus was very small $(2$ in. $(5 \mathrm{~cm}$.) by sound) and the external os was flush with the vaginal vault. There was some senile vaginitis. The electrocardiogram was normal. Glucose-tolerance tests gave flat curves.

Comment.-This patient presumably sustained a postpartum necrosis of only moderate severity; it seems quite possible that almost a quarter of the anterior lobe remained alive. The resultant syndrome is thus only a partial one and is little more than a superinvolution of the uterus. The biochemical investigations show only minor deviations from the normal.

\section{REFERENCES}

Cooke, R. T. (1945). British Medical Journal, 2, 493. Sheehan, H. L., and Summers, V. K. (1949). Quart. J. Med., 28, 319.

An appeal has been made by Sir Oliver Harvey, the British Ambassador in Paris, on behalf of the Hertford British Hospital. This hospital, which has given attention to so many British subjects, was opened in Paris in 1879, the product of close AngloFrench friendship in the latter half of the nineteenth century. It was founded by Sir Richard Wallace, and on his death the buildings were made over to the British Government. Its affairs were managed by a committee of prominent members of the British colony and of the Embassy staff. To-day the Hertford Hospital has more than 60 beds, with wards for chronic cases and destitute patients, and a modern maternity block. There are up-to-date operating theatres and $x$-ray services, and a large out-patients' department with a dental section. The residents and nursing staff are British, and they are supported by many leading French consultants. The financial burdens of the hospital in recent years have increased alarmingly. The recent Anglo-French reciprocal social security agreement has not helped the hospital, because British subjects resident in France for less than six months are excluded from the right to free treatment. Unless the year's estimated deficit of $£ 10,000$ is made up there will be no course for the hospital but to close its doors, an event which Sir Oliver describes as unthinkable. Contributions may be sent to the Ambassador, c/o the Hospital Secretary, 48, rue de Villiers, Levallois, Seine. 